\title{
MART-1 peptide vaccination plus IMP321 (LAG-3lg fusion protein) in patients receiving autologous PBMCs after lymphodepletion: results of a Phase I trial
}

Emanuela Romano ${ }^{1,2,3}$, Olivier Michielin 1,3, Verena Voelter ${ }^{1}$, Julien Laurent ${ }^{2,6}$, Hélène Bichat ${ }^{2}$, Athina Stravodimou', Pedro Romero ${ }^{3}$, Daniel E Speiser ${ }^{3}$, Frédéric Triebel ${ }^{5}$, Serge Leyvraz ${ }^{1,2^{*} \dagger}$ and Alexandre Harari ${ }^{2,3,4+}$

\begin{abstract}
Background: Immunotherapy offers a promising novel approach for the treatment of cancer and both adoptive T-cell transfer and immune modulation lead to regression of advanced melanoma. However, the potential synergy between these two strategies remains unclear.

Methods: We investigated in 12 patients with advanced stage IV melanoma the effect of multiple MART-1 analog peptide vaccinations with $(n=6)$ or without $(n=6)$ IMP321 (LAG-3lg fusion protein) as an adjuvant in combination with lymphodepleting chemotherapy and adoptive transfer of autologous PBMCs at day (D) 0 (Trial registration No: NCT00324623). All patients were selected on the basis of ex vivo detectable MART-1-specific CD8 T-cell responses and immunized at D0, 8, 15, 22, 28, 52, and 74 post-reinfusion.

Results: After immunization, a significant expansion of MART-1-specific CD8 T cells was measured in $83 \%(n=5 / 6)$ and $17 \%(n=1 / 6)$ of patients from the IMP321 and control groups, respectively $(P<0.02)$. Compared to the control group, the mean fold increase of MART-1-specific CD8 T cells in the IMP321 group was respectively $>2-,>4$ - and $>6$-fold higher at D15, D30 and D60 $(P<0.02)$. Long-lasting MART-1-specific CD8 T-cell responses were significantly associated with IMP321 $(P<0.02)$. At the peak of the response, MART-1-specific CD8 T cells contained higher proportions of effector $\left(C C R 7^{-} \mathrm{CD}^{-} 5 \mathrm{RA}^{+/-}\right)$cells in the IMP321 group $(P<0.02)$ and showed no sign of exhaustion (i.e. were mostly PD1 ${ }^{-} \mathrm{CD} 160^{-} \mathrm{TIM}^{-} \mathrm{LAG} 3^{-} 2 \mathrm{~B}^{+/-}$). Moreover, IMP321 was associated with a significantly reduced expansion of regulatory $T$ cells $(P<0.04)$; consistently, we observed a negative correlation between the relative expansion of MART-1-specific CD8 T cells and of regulatory T cells. Finally, although there were no confirmed responses as per RECIST criteria, a transient, 30-day partial response was observed in a patient from the IMP321 group.
\end{abstract}

Conclusions: Vaccination with IMP321 as an adjuvant in combination with lymphodepleting chemotherapy and adoptive transfer of autologous PBMCs induced more robust and durable cellular antitumor immune responses, supporting further development of IMP321 as an adjuvant for future immunotherapeutic strategies.

Keywords: Melanoma, Immunotherapy, Immunization, Adjuvant, Immunogenicity, LAG-3lg, Tumor-specific CD8 T cells, Adoptive cell therapy

\footnotetext{
* Correspondence: Serge.Leyvraz@chuv.ch

${ }^{\dagger}$ Equal contributors

'Department of Oncology, Service of Medical Oncology, CHUV BH-06 1011

Lausanne, Switzerland

${ }^{2}$ Laboratory of tumor immunobiology, Department of Oncology, University

Hospital of Lausanne, Lausanne, Switzerland

Full list of author information is available at the end of the article
} 


\section{Background}

Recent advances in the understanding of the complex cellular interactions regulating cancer immunity have led to new strategies in the development of cancer immunotherapy. There is strong evidence that both adoptive Tcell transfer and T-cell checkpoint blockade can lead to regression of advanced melanoma [1-4]. Adoptive cell therapy using tumor-infiltrating lymphocytes (TILs) can mediate objective and durable tumor regressions in patients with metastatic melanoma; however, melanoma samples cannot be obtained for TIL production from all patients and, in some cases, TIL cannot be isolated from the resected tumor. To overcome those potential limitations, we capitalized on the adoptive transfer of peripheral blood mononuclear cells (PBMCs), with the hypothesis that the vaccine would prime newly infused $\mathrm{T}$ cells to mediate tumor response.

In murine models and in early clinical trials, lymphodepletion seemed to enhance the antitumor effects of transferred $\mathrm{T}$ cells in vivo by several mechanisms including the elimination of suppressive regulatory $\mathrm{T}$ lymphocytes (Tregs) [5], the elimination of cellular "sinks" for homeostatic cytokines such as IL-7 and IL-15 [6], and the engagement of toll-like receptors on antigen-presenting cells after damage of the gut epithelium $[7,8]$. In these murine models, there was a direct relationship between the extent of lymphodepletion and the magnitude of the in vivo antitumor effect of the transferred cells.

In our prior clinical trial $[9,10]$, patients with advanced stage III/IV melanoma received a lymphodepleting, nonmyeloablative chemotherapy consisting of Busulfan and Fludarabine before adoptive transfer of autologous PBMCs and MART-1 analog peptide vaccination. This conditioning regimen induced a suboptimal lymphodepletion at the time of cell infusion and was associated to a prolonged lymphopenia affecting long-term immune reconstitution. We reported a long-lasting (over 2 years) objective response in 1 out of 6 patients [9]. In a subsequent clinical phase I trial, we tested whether the use of a different lymphodepleting regimen of Cyclophosphamide (CTX) at $30 \mathrm{mg} / \mathrm{kg}$ or at $60 \mathrm{mg} / \mathrm{kg}$ plus Fludarabine at $30 \mathrm{mg} / \mathrm{m}^{2}$ followed by adoptive transfer of autologous PBMCs and vaccination with MART-1peptide emulsified in Incomplete Freund's Adjuvant (IFA) would increase the expansion in vivo of tumor-specific $\mathrm{T}$ cells and induce a stronger anti-tumor protection [10]. We showed that CTX plus Fludarabine was superior to Busulfan plus Fludarabine conditioning in terms of degree of lymphodepletion, with a maximal effect obtained with a CTX dose of $60 \mathrm{mg} / \mathrm{kg}$, and that reconstitution of T cells, particularly of CD8 T cells, was more rapid. We reported that the depth of homeostatic T-cell proliferation correlated tightly with the extent of lymphodepletion and was accompanied by increased levels of IL-15 but not of IL-7; however, despite efficient homeostatic proliferation of total CD4 and CD8 $\mathrm{T}$ cells, the frequency of CD8 T cells specific for MART-1 and cancer-testis antigens were quite low. In contrast, we observed a substantial proliferation of EBV-specific T cells; whether this was due to homeostatic proliferation or viral reactivation remains to be established [10].

Another question that remains so far unanswered is whether the association of tumor-peptide vaccination combined with a stronger adjuvant after adoptive cell transfer would induce a more sustained anti-tumor specific CD8 T-cell expansion and potentially counterbalance the homeostatic proliferation of Tregs in vivo. A large body of work supports the idea that immunogenicity of a vaccine preparation is critical to induce measurable antigen-specific T-cell responses in vivo. Vaccines containing peptides mixed with IFA alone elicit only moderate CD8 T lymphocyte-mediated responses [11].

Lymphocyte activation gene-3 (LAG-3 or CD223) protein is an important regulator of T-cell homeostasis [12]. It is a non-TLR (toll-like receptor) activator of antigenpresenting cells (APCs) and induces dendritic cells (DCs) migration and antigen cross-presentation to CD8 T cells. It binds to MHC class II molecules that normally present antigenic peptides to CD4 T cells. LAG-3 is evolutionarily related to $\mathrm{CD} 4$ and has retained an affinity of 2 logs higher than CD4 for their common ligand, MHC II molecules on APCs such as dendritic cells. A soluble form of the LAG-3 (sLAG-3) molecule that is derived from an alternative splicing event can be found in human serum. In a study, breast cancer patients who had high levels of sLAG-3 in their sera at diagnosis were shown to have a better overall survival than patients with low sLAG-3 levels [13].

Based on these observations, a dimeric recombinant IMP321 molecule has been produced cGMP, consisting of the four LAG-3 extracellular Ig-like domains fused to the Fc fraction of a human IgG1 (LAG-3Ig). IMP321 acts as an APC activator and is a novel adjuvant that induces potent antigen-specific CD8 T-cell responses. Non-TLR agonists like CD40L or LAG-3Ig are human proteins that promote DC maturation and migration [14-17], as well as to support the antigen-cross-presentation to a greater extent than other commonly used adjuvants [18]. In the present study, we set out to address the question whether the combination of lymphodepleting chemotherapy of CTX at $30 \mathrm{mg} / \mathrm{kg}$ followed by Fludarabine at $30 \mathrm{mg} / \mathrm{m}^{2}$ and adoptive transfer of autologous PBMCs in association to a MART-1 peptide vaccination with or without the presence of the adjuvant IMP321 would elicit a more robust and long-lasting anti-tumor immunity that would finally improve patient outcome. Our study showed a more robust and durable expansion of MART-1-specific CD8 T cells in the IMP321 group, associated to only transient clinical response in one patient. 


\section{Methods}

\section{Study groups}

The present trial was approved by the local IRBs and by the Swiss national regulatory authority (Swissmedic). It has been registered in the NCI Clinical Trials PDQ under the number NCT00324623. Patients with stage IV cutaneous melanoma were accrued between October 2005 and August 2011. Eligibility was based on the following inclusion criteria: progressive disease with no evidence of brain metastases, HLA-A2 positivity; tumor expression of Melan-A by IHC; and a measurable, endogenous anti-MART-1 CD8 T-cell response for patients that had no prior adjuvant vaccine therapy, as described [10]. MART-1 CD8 T-cell responses were assessed by tetramer staining using ELAGIGILTV-MHC class I multimers with a threshold of $0.03 \%$ of CD8 T cells above background. Patients underwent CT scan of the thorax, abdomen, and pelvis within 4 weeks of therapy. After collection of peripheral blood mononuclear cells (PBMCs) by lymphocytapheresis, patients received alymphodepleting chemotherapy. Patients received 2 days (D7 and D-6) of CTX at $30 \mathrm{mg} / \mathrm{kg}$, followed by 3 days (D-5 to D-3) of Fludarabine at $30 \mathrm{mg} / \mathrm{m}^{2}$. Three days later (D0), cryopreserved PBMCs $\left(8.9 \pm 0.86 \times 10^{9}\right)$ with a mean $90 \%$ viability were reinfused (individual patient's numbers are provided in Additional file 1: Table S1), and peptide vaccination with the MART-1 analog peptide (MART- $1_{26-35}$, A27L (ELAGIGILTV), LICR MelbourneAustin Branch) emulsified in Incomplete Freund's Adjuvant IFA-51 (IFA; Seppic Inc, France) was given subcutaneously (s.c.) at D8, 15, 22, 28, 52, and 74 postreinfusion as described [11,19]. IMP321 (LAG-3Ig fusion protein, Immutep S.A., Orsay, France) was added to the vaccine for 6 of the 12 patients, at a final concentration of $25 \mu \mathrm{g}$ (3 patients) and $250 \mu \mathrm{g}$ ( 3 patients). Blood samples for immunomonitoring were collected before each vaccine. G-CSF at $5 \mu \mathrm{g} / \mathrm{kg}$ was given s.c. starting at D1 until absolute neutrophil counts (ANC) reached $>1000$ cells $/ \mu \mathrm{L}$. All patients received at least 6 -month of TMP/SMX prophylaxis and until CD4 T-cell counts were $>200$ cells $/ \mu \mathrm{L}$. Patients with positive serology for HSV at baseline received antiviral prophylaxis with valaciclovir until recovery of neutropenia (ANC $>1000$ cells $/ \mu \mathrm{L}$ ).

Synthetic peptide and peptide-MHC class I multimer complex HPLC-purified (>80\% purity) MART-1 analog peptide (MART- $1_{26-35}$, A27L, ELAGIGILTV) was obtained from LICR (Melbourn-Austin Branch) and ELAGIGILTVMHC class I multimers were purchased from ProImmune (Oxford, UK). HLA-A2 restricted Influenza (Flu, GILGFVFTL), Epstein-Barr Virus (EBV, GLCTLVAML) and Cytomegalovirus (CMV, NLVPMVATV) peptides were purchased from JPT (JPT Peptide Technologies $\mathrm{GmbH}$, Germany).

\section{Antibodies}

The following Abs were used in different combinations. CD8-PB, CD8-APCH7, CD3-APCH7, CD45RA-PECy5, PD-1-FITC, IFN- $\gamma$-APC, TNF- $\alpha$-PECy7, and IL-2-PE were purchased from Becton Dickinson (BD, San Diego, CA), CD4-ECD, CD3-ECD, CD28-ECD, CD27-APC from Beckman Coulter (Fullerton, CA, USA), perforinFITC (clone B-D48) from Diaclone (Besançon, France), CCR7-FITC from R\&D Systems (Minneapolis, MN, USA), 2B4-PE-Cy5.5 and CD160-APC from Biolegend (San Diego, CA, USA) and CD127-PE-Cy7 from eBioscience (San Diego, CA, USA).

\section{Flow cytometer}

All flow cytometry analyses from the study were performed on an LSRII Becton Dickinson (BD, San Diego, CA) SORP (4 lasers). Daily maintenance of the flow cytometer and optimal settings were determined using $\mathrm{BD}$ CS\&T bright bead target values for each fluorescence detector, to obtain consistent and reproducible results over time.

\section{Ex vivo analysis of tumor-specific CD8 T cells}

Cryo-preserved blood mononuclear cells $\left(1-2 \times 10^{6}\right)$ cells were stained for dead cells (Aqua LIVE/DEAD, Invitrogen) and then stained with appropriately tittered peptide-MHC class I multimer complexes at $4^{\circ} \mathrm{C}$ for $30^{\prime}$ in $\mathrm{Ca}^{2+}$-free media as described [20]. Cells were then washed and directly stained at $4^{\circ} \mathrm{C}$ for $20^{\prime}$ with the following Abs in various combinations: CD3, CD8, CD45RA, CD127, CCR7, CD28, CD27, PD-1, 2B4, CD160. Finally, cells were fixed (CellFix, BD), acquired on an LSRII SORP and analyzed using FlowJo 8.8.2 (Tree star Inc, USA). Analysis and presentation of distributions was performed using SPICE version 5.1, downloaded from $<\mathrm{http} / / /$ exon. niaid.nih.gov/spice> [21]. The number of lymphocytegated events ranged between $0.6-1 \times 10^{6}$ in the flow cytometry experiments.

\section{ICS assay}

Cryo-preserved blood mononuclear cells $\left(1-2 \times 10^{6}\right)$ were stimulated overnight in $1 \mathrm{ml}$ of complete media (RPMI (Invitrogen), 10\% fetal bovine serum (FBS; Invitrogen), $100 \mu \mathrm{g} / \mathrm{ml}$ penicillin, $100 \mathrm{unit} / \mathrm{ml}$ streptomycin (BioConcept)) in the presence of Golgiplug $(1 \mu \mathrm{l} / \mathrm{ml}, \mathrm{BD})$, anti-CD28 $(0.5 \mu \mathrm{g} / \mathrm{ml}, \mathrm{BD})$ and $1 \mu \mathrm{g} / \mathrm{ml}$ of peptide as described [22]. Staphylococcus enterotoxin B (SEB; Sigma) stimulation $(100 \mathrm{ng} / \mathrm{ml})$ served as positive control. At the end of the stimulation period, cells were stained for dead cells (Aqua LIVE/DEAD, Invitrogen), permeabilized (Cytofix/Cytoperm, BD) and then stained at RT for 20 ' with CD4, CD8, CD3, IFN- $\gamma$, IL-2, TNF- $\alpha$ and perforin (clone B-D48). Cells were then fixed (CellFix, $\mathrm{BD}$ ), acquired on an LSRII SORP and analyzed using 
FlowJo 8.8.2. Analysis and presentation of distributions was performed using SPICE version 5.1, downloaded from <http://exon.niaid.nih.gov/spice> [21].

\section{IFN- $\gamma$ ELISpot assay}

After 7-day antigen-specific stimulation with HLA-A2+, MART-1 ${ }_{26-35}$-loaded T2 cells at 1:10 APC:T cell ratio, responder lymphocytes were tested for IFN- $\gamma$ production by ELISpot assay (1-DIK ELISpot for human IFN- $\gamma$, Mabtech, DiaPharma Group; Vector ABC kit, Vector Laboratories; Automated ELISpot Bioreader 5000, BIO-SYS $\mathrm{GmbH}$ ) according to the manufacturer's instructions. Targets for lymphocyte restimulation during overnight rechallenge in the ELISpot assays were either MART126-35-pulsed, unpulsed T2, or HLA-A2+, MART-1+ melanoma Me205 cell lines, plated in triplicates at 30:1 effector:target (E:T) ratio. Control wells contained effectors with unloaded T2 targets. Me275 is a human cell line derived from a nodal metastasis of melanoma.

\section{Functional avidity}

Peptide stimulations were performed as described above. Functional avidity of responses was assessed by performing limiting peptide dilutions and determining the peptide concentration required to induce half-maximal IFN- $\gamma$ responses in in vitro assays as described [23]. Peptides were added in serial dilutions ranging from $2 \mu \mathrm{g} / \mathrm{ml}$ to $1 \mathrm{pg} / \mathrm{ml}$. $\mathrm{EC}_{50}$ was determined as the peptide concentration needed to achieve a half-maximal response.

\section{Statistical analysis}

Unpaired and paired two-tailed student $t$-tests were performed using Excel (Microsoft, Redmond, WA), or GraphPad Prism version 5.03 (San Diego, CA). Correlations among variables were performed by Spearman's test. Regarding SPICE analyses of the flow-cytometry data, comparison of distributions was performed using a Student's $t$-test and a partial permutation test as described [21].

\section{Results}

\section{Demographics and treatment-related toxicity}

In this study, we investigated the safety of the combination of lymphodepletion and adoptive cell transfer (ACT) of autologous PBMCs in association to a MART1-peptide vaccination with or without the presence of the adjuvant IMP321 and whether it would elicit a more robust and long-lasting anti-tumor immunity that could ultimately improve patients outcome. Twelve HLA-A2+ patients with stage IV cutaneous melanoma and ex vivo detectable MART-1-specific CD8 T-cell responses were treated. Initial frequencies of circulating MART-1specific CD8 T cells prior to intervention were balanced between the IMP321 and No IMP321 patient groups
(Additional file 2: Figure S1A). Patients were immunized s.c. with a MART-1 peptide at day (D) $0,8,15,22,28$, 52 , and 74 post-reinfusion with $(\mathrm{n}=6)$ or without $(\mathrm{n}=$ 6) IMP321 as an adjuvant in combination with lymphodepleting chemotherapy and adoptive transfer of autologous PBMCs. Patient gender was balanced in the IMP321 group, as opposed to the no IMP321 group where $66 \%$ patients were male $(P=0.6, \mathrm{~ns})$. Mean age was 54 (range, 35 to 73 years, $P=0.3$, ns). ECOG performance status was 0 to 1 for all patients. The majority of patients had stage IV M1a (3 of 6 patients, 50\%) and M1c disease (4 of 6 patients, 66\%) in the IMP321 and no IMP321 group, respectively. Four patients (66.6\%) had prior chemo- or radiotherapy in the IMP321 group and 1 patient (16.6\%) in control group, respectively. All patients in this study had previous adjuvant immunotherapy (MART-1-containing anti-tumor vaccines) for their high-risk disease. Demographic data are listed in Table 1. As expected, hematologic toxicity was frequent in both groups with all patients experiencing grade 3-4 leucopenia and CD4 T-cell lymphopenia. Febrile neutropenia was reported in $50 \%$ of the patients in the IMP321 group and $33 \%$ of the patients in the control group, and resolved without clinical complications. Non-hematological toxicities, as reported in Table 2, were mild.

\section{Table 1 Patient Demographics}

\begin{tabular}{lll}
\hline & IMP321 & No IMP321 \\
& N (\%) & N (\%) \\
\hline Age & & \\
Median & 49.5 & 56.8 \\
Range & $35-73$ & $48-70$ \\
Gender & & \\
Male & $3(50 \%)$ & $4(66.6 \%)$ \\
Female & $3(50 \%)$ & $2(33.3 \%)$ \\
ECOG PS & & \\
0 & $4(66.6 \%)$ & $5(83.3 \%)$ \\
1 & $2(33.3 \%)$ & $1(16.6 \%)$ \\
M sub-stage & & $1(16.6 \%)$ \\
M1a & $3(50 \%)$ & $1(16.6 \%)$ \\
M1b & $1(16.6 \%)$ & $4(66.6 \%)$ \\
M1c & $2(33.3 \%)$ & \\
Previous therapy for Stage IV & $2(33.3 \%)$ \\
Surgery & $1(16.6 \%)$ & $1(16.6 \%)$ \\
CHT or RT & $2(33.3 \%)$ & $0(0 \%)$ \\
Other & $2(33.3 \%)$ & $6(100 \%)$ \\
Adjuvant immunotherapy & & $0(0 \%)$ \\
Yes & $6(100 \%)$ & \\
No & $0(0 \%)$ & \\
\hline
\end{tabular}


Table 2 Treatment-related adverse events

\begin{tabular}{|c|c|c|c|c|}
\hline & No IMP321 N (\%) & IMP321 N (\%) & No IMP321 N (\%) & IMP321 N (\%) \\
\hline \multicolumn{5}{|l|}{ Treatment-related event } \\
\hline Non-hematological & Grade 1-2 & & Grade 3-4 & \\
\hline Fatigue & $6(100 \%)$ & $6(100 \%)$ & - & - \\
\hline Nausea/Nomiting & $5(83 \%)$ & $1(16.6 \%)$ & - & - \\
\hline Constipation & - & - & $1(16.6 \%)$ & - \\
\hline Alopecia & $6(100 \%)$ & $6(100 \%)$ & - & - \\
\hline Mucositis (oral) & - & $1(16.6 \%)$ & - & - \\
\hline Weight loss & $6(100 \%)$ & $6(100 \%)$ & - & - \\
\hline \multicolumn{5}{|l|}{ Hematological } \\
\hline Anemia & $4(66.6 \%)$ & $5(83 \%)$ & $1(16.6 \%)$ & $1(16.6 \%)$ \\
\hline Leucopenia & - & - & $6(100 \%)$ & $6(100 \%)$ \\
\hline Trombocitopenia & - & $4(66.6 \%)$ & $4(66.6 \%)$ & $2(33 \%)$ \\
\hline Febrile Neutropenia (grade 3) & $\mathrm{n} / \mathrm{a}$ & $\mathrm{n} / \mathrm{a}$ & $2(33 \%)$ & $3(50 \%)$ \\
\hline CD4 Lymphopenia ( $\geq$ grade 3 ) & $\mathrm{n} / \mathrm{a}$ & $\mathrm{n} / \mathrm{a}$ & $6(100 \%)$ & $6(100 \%)$ \\
\hline
\end{tabular}

\section{Stronger expansion of MART-1-specific CD8 T-cell} responses following immunization in the IMP321 group Using peptide-MHC class I multimer complexes, we monitored the frequency of circulating MART-1-specific CD8 T cells on viable $\mathrm{CD}^{+} \mathrm{T}$ cells in peripheral blood from patients from both groups (Figure 1A). Analyses were performed at D15, D30 and D60 post-ACT and immunization and were compared to D-15, i.e. prior to treatment. As shown in the representative examples from Figure $1 \mathrm{~A}$ and $\mathrm{B}$, the frequency of MART-1-specific CD8 T cells significantly increased after immunization in the IMP321 group but not in the control (no IMP321) group. Of note, no dose-effect was observed at the $25 \mu \mathrm{g}$ and $250 \mu \mathrm{g}$ IMP321 dose levels; therefore, all patients receiving IMP321 are pooled in the present analyses. Cumulative analyses confirmed a significant expansion (defined as three-fold higher than baseline) of MART-1-specific CD8 T cells in 5 out of 6 patients (83\%) from the IMP321 group compared to only 1 out of 6 patients (17\%) from the control group $(P<0.02$, Figure $1 \mathrm{C}$ ). Furthermore, compared to the control group, the mean fold increase of MART-1-specific CD8 T cells was respectively $>2$-, $>4$ - and $>6$-fold higher in the IMP321 group at D15, D30 and D60. Consistently with our prior study [10], we observed in the control arm (no IMP321) a progressive and profound decrease in the frequency of MART-1-specific CD8 T cells starting at D15 and still notable at D30 and D60 (Figure 1D). Interestingly, IMP321 appears not only to prevent this drop but also to lead to an increase in the frequency of MART-1-specific CD8 T cells. IMP321 immunization was therefore also associated to the induction of a durable MART-1-specific CD8 T-cell response at D60, which remained higher than baseline and was significantly higher than in the control group $(P<0.02$, Figure 1D). Of note, absolute leukocyte counts and percentages of CD4 and CD8 T-cells were comparable between the two arms (Additional file 2: Figure S1), thus indicating that the aforementioned differences in the frequency of circulating MART-1-specific CD8 T cells also reflected absolute counts of these cells. Taken together, these observations indicate that vaccination with IMP321 was more immunogenic and lead to a selectively stronger and more durable anti-tumor cellular immune response.

\section{Immunization with IMP321 induces more effector MART-1-specific CD8 T-cell responses}

We then performed qualitative analyses of MART-1specific CD8 T cells at the peak of response for each of the patients from the IMP321 or control groups. We first investigated the level of $\mathrm{T}$-cell differentiation of vaccineinduced MART-1-specific CD8 T cells and analyzed the expression of CD45RA and CCR7. MART-1-specific CD8 $\mathrm{T}$ cells from patients of the IMP321 groups were mostly composed of CD45RA ${ }^{-} \mathrm{CCR}^{-}$and of $\mathrm{CD}^{-} 5 \mathrm{RA}^{+} \mathrm{CCR} 7^{-}$, i.e. two subsets of effector cells, whereas significantly higher proportions of $\mathrm{CD}_{45 \mathrm{RA}}^{+} \mathrm{CCR}^{+}$and $\mathrm{CD}_{45 \mathrm{RA}}{ }^{-} \mathrm{CCR} 7^{+}$, i.e. naïve and central memory cells, were observed in the control group (Figure 2A-B). These observations indicate that vaccination with IMP321 was selectively associated with the induction of a more effector anti-tumor immunity.

\section{Functional potency of MART-1-specific CD8 T-cell responses following immunization}

We then comprehensively assessed the functional profile and effector function of MART-1-specific CD8 T cells at the peak of responses. For this purpose, cryopreserved PBMC were thawed and stimulated with a panel of cognate tumor- or viral antigens and their ability to produce key cytokines (i.e. IFN- $\gamma$, IL-2 and/or TNF- $\alpha$ ) and to 


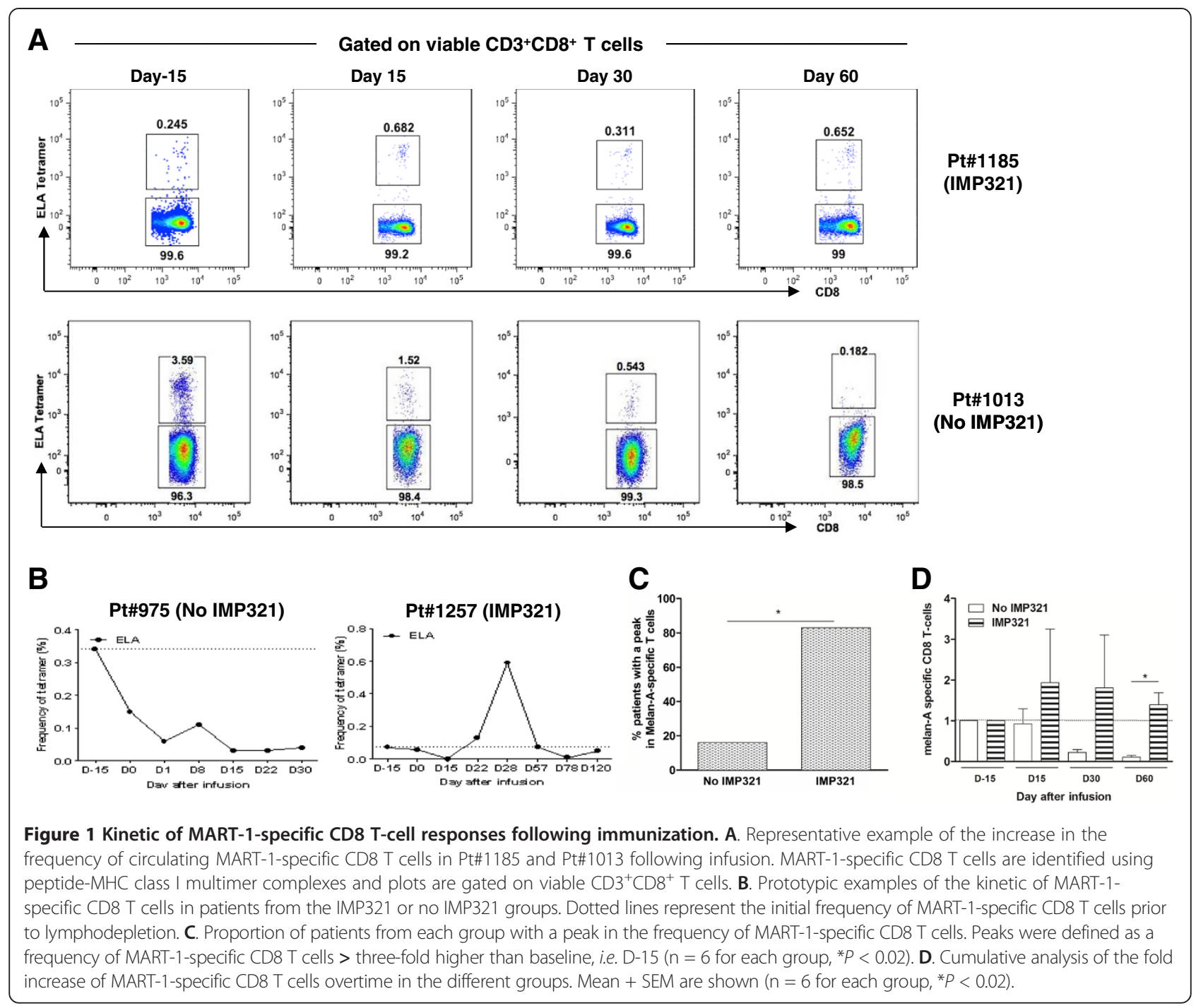

express the cytolytic marker perforin were assessed using polychromatic flow cytometry. Of note, the functional profile of MART-1-specific CD8 T cells was compared to that of an extensive set of virus-specific (i.e. Cytomegalovirus [CMV], Epstein Barr virus [EBV] and influenza [Flu]) CD8 T cells. Of interest, as shown in the representative example of Pt\#629 from the IMP321 group, MART-1specific CD8 $\mathrm{T}$ cells showed a level of polyfunctionality comparable to that of CMV-specific CD8 T cells (i.e. were mostly IFN- $\gamma^{+} / \mathrm{TNF}^{-} \alpha^{+} / \mathrm{IL}^{-2}{ }^{+/-} /$perforin $^{+/}$; Figure $3 \mathrm{~A}$ ). Conversely, consistently with previous studies [24,25], EBV- and Flu-specific CD8 T cells contained a higher proportion of IL-2-producing cells and showed lower perforin expression as compared to MART-1-specific CD8 T cells (Figure 3A). Furthermore, MART-1-specific CD8 T cells secreted IFN- $\gamma$ upon recognition of cognate Ag presented at the cell surface of either a peptide-loaded T2 cell line or naturally expressed by the melanoma cell line Me275 (Figure 3B). Taken together, these data demonstrate that
MART-1-specific CD8 $\mathrm{T}$ cells are polyfunctional and can recognize MART-1-expressing melanoma cells.

\section{No evidence of T-cell exhaustion of MART-1-specific CD8 T-cell responses following immunization}

As a subsequent qualitative analysis, we investigated the level of inhibitory receptor expression ("exhaustion markers") by vaccine-induced MART-1-specific CD8 T cells. To this end, we analyzed the expression of PD-1, 2B4, CD160, LAG3, and TIM-3 on MART-1-specific CD8 $\mathrm{T}$ cells at the peak of response for each of the patients from the IMP321 or control groups. Of interest, the majority of MART-1-specific CD8 T cells in patients from the IMP321 or no IMP321 groups were composed of cells lacking all the markers analyzed (i.e. were mostly $\mathrm{PD}^{-}{ }^{-} \mathrm{B} 4^{-} \mathrm{CD} 160^{-} \mathrm{LAG}^{-} \mathrm{TIM}^{-}$) or only expressed $2 \mathrm{~B} 4$ (Figure 4A-B). However, as compared to the IMP321 group, a significantly higher proportion of MART-1-specific CD8 $\mathrm{T}$ cells from the control group co-expressed PD-1 and 2B4 


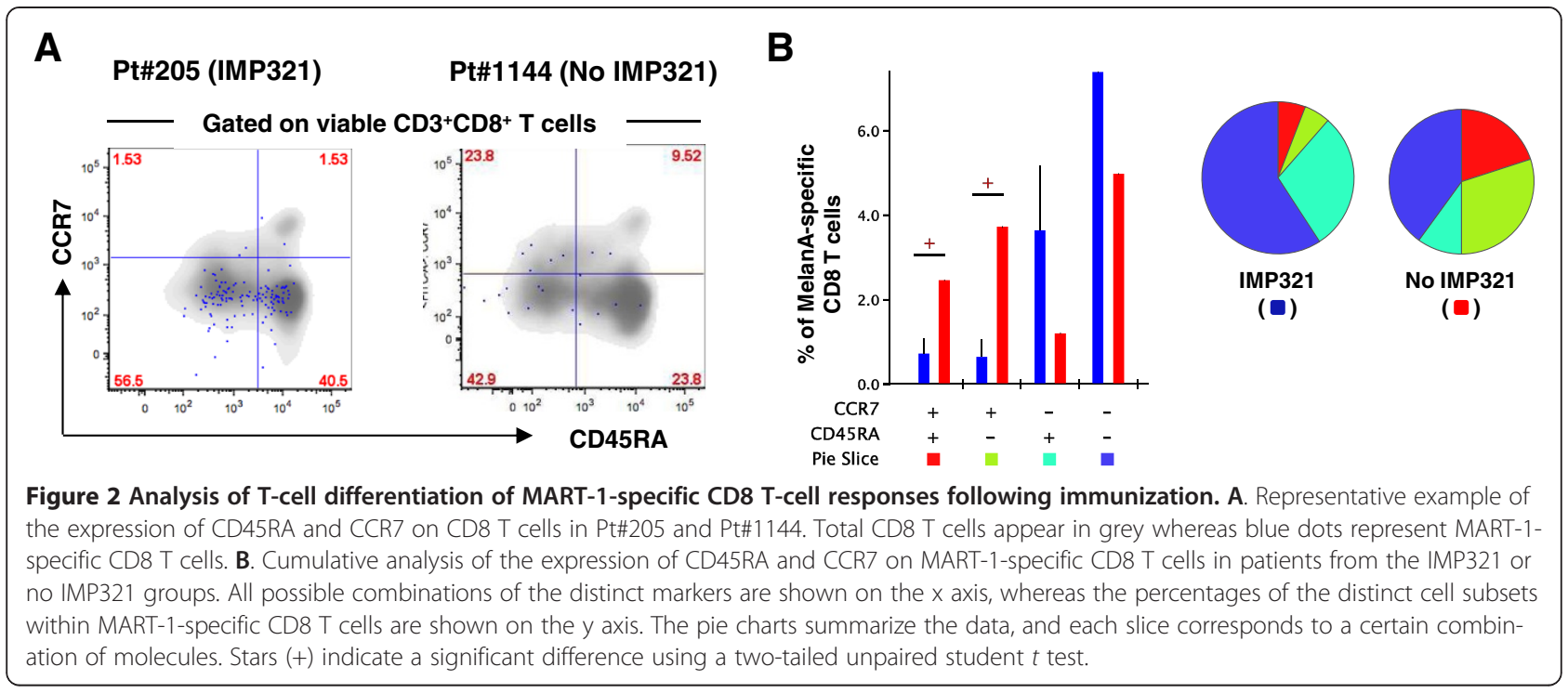

(Figure 4B). Taken together, these observations indicate that vaccination with IMP321 does not lead to the induction of MART-1-specific CD8 $\mathrm{T}$ cells with a typical exhausted phenotype.

\section{Increase in the functional avidity of MART-1-specific CD8} T cells in patients from the IMP321 group

Functional avidity in an important feature of T-cell immunity [26]. We investigated whether the present experimental strategy would lead to changes in the functional avidity of MART-1-specific CD8 T cells. For this purpose, PBMC were stimulated with limiting dilutions of MART-1 peptides and the functional avidity of CD8 T-cell responses was assessed by determining the peptide concentration required to induce half-maximal IFN- $\gamma$ responses (i.e. $\mathrm{EC}_{50}$ ). Interestingly, when we compared cells isolated at baseline or 2 months after treatment, we observed a significant increase in the functional avidity of MART-1-specific CD8 T cells $(P<$ 0.05, Additional file 3: Figure S2).

\section{Reduced expansion of regulatory $\mathrm{T}$ cells following immunization with IMP321}

As mentioned above, lymphodepletion may enhance the antitumor effects of transferred $\mathrm{T}$ cells by inducing the elimination of suppressive regulatory $\mathrm{T}$ lymphocytes (Tregs) [5]. We then analyzed the frequency of Tregs, defined as $\mathrm{CD}^{+} \mathrm{CD}^{+}{ }^{+} \mathrm{CD} 25^{\text {high }} \mathrm{FOXP3}^{+}$, on live $\mathrm{T}$ cells in patients from the IMP321 or control groups. We observed that the frequency of Tregs was significantly higher in the control group compared to the IMP321 group (Figure 5A and $\mathrm{B}$ ). We then also confirmed that the above gating strategy allowed the identification of true regulatory $\mathrm{T}$ cells. As shown in Figure 5A, 80-90\% of $\mathrm{CD}^{+} \mathrm{CD}^{+} \mathrm{CD}_{25} 5^{\text {high }} \mathrm{FOXP}^{+}{ }^{+}$were $\mathrm{CD} 45 \mathrm{RO}^{+} \mathrm{CD}_{127}{ }^{-}$, thus demonstrating that IMP321 immunization selectively prevented the expansion of adaptive Tregs. Of note, absolute leukocyte counts and percentages of CD4 Tcells were comparable between the two arms (Additional file 2: Figure S1B and $\mathrm{C}$ ), thus indicating that the aforementioned differences in the frequency of circulating Tregs also reflected absolute counts of these cells.

Finally, we also investigated the potential relationship between the expansion of MART-1-specific CD8 T cells and of Tregs in both groups. Interestingly, we observed a significant negative correlation between the fold increase of MART-1-specific CD8 T cells and that of Tregs (Figure $5 \mathrm{C}$ ), thus suggesting a potential mechanism for the selective expansion of MART-1-specific CD8 T cells in the IMP321 group.

\section{Discussion}

Current approved therapeutic options in the US and Europe for patients with metastatic melanoma include dacarbazine, interleukin-2, ipilimumab, vemurafenib, dabrafenib, and trametinib, but long-term tumor regression using available agents remains out of reach for most patients. Adoptive cell transfer (ACT) with autologous tumor-infiltrating lymphocytes (TILs) has shown encouraging results in clinical trials, with evidence of durable ongoing complete responses in patients with advanced melanoma. However, melanoma samples cannot be obtained for TIL production from all patients and, in some cases, TILs cannot be isolated from the resected tumor. To overcome those potential limitations, we capitalized on the adoptive transfer of PBMCs in combination with a MART-1 peptide vaccination supplemented or not with IMP321. In this phase I study we included a total of twelve, previously treated, advanced melanoma patients. All the patients were HLA-A*0201 


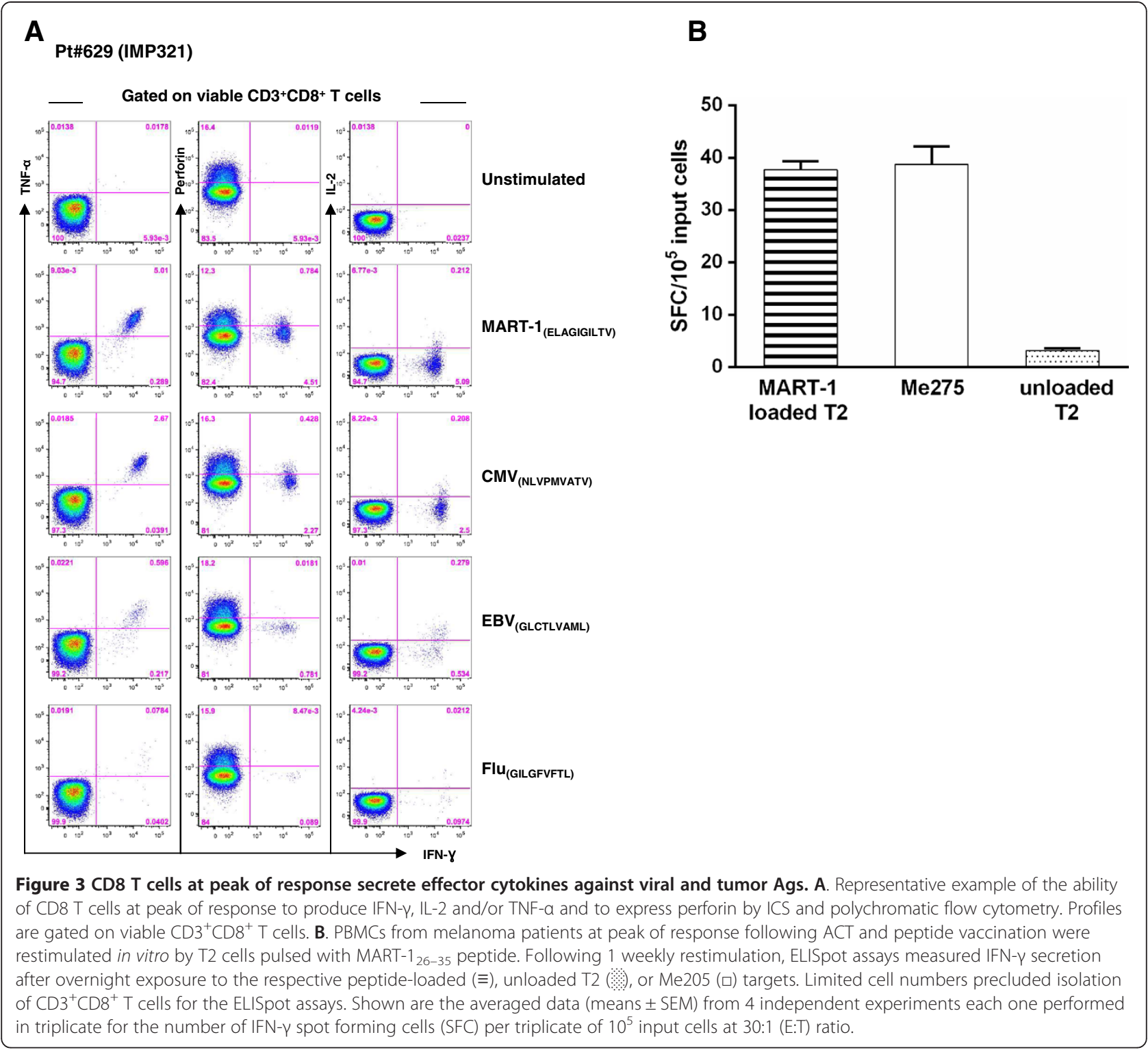

positive and had a detectable frequency of MART-1reactive $\mathrm{T}$ cells at baseline. Age and gender were balanced between groups, as opposed to disease stage distribution with a preponderance of subjects with worst prognosis (66.6\% vs $33.3 \%$ stage IV M1c) in the no IMP321 group. Similar to previously reported ACT studies, the toxicities reported in our trial were mostly hematological and related to the lymphodepleting conditioning regimen.

We set a high threshold (3-fold increase from baseline) to define a MART-1-specific immune response, and IMP321-supplemented vaccines stimulated significantly greater and more sustained MART-1 tetramer reactivity than the control group, suggesting that the addition of a vaccine adjuvant such as the IMP321 is essential for boosting anti-tumor immunity. No systemic dose-effect was observed, however, at the $25 \mu \mathrm{g}$ and $250 \mu \mathrm{g}$ IMP321 dose levels, because such low doses were expected to elicit local or loco-regional activation of skin APCs; whereby, an IMP321 dose of $6 \mathrm{mg}$ promoted a systemic effect in a pharmacokinetic study in patients with advanced renal cell carcinoma [27]. Our data also show that IMP321 is essential to prevent the decrease in tumor-specific CD8 T cells observed without IMP321 [10]. These observations are in agreement with previous studies, showing increased CD8 T cells and NK cell production of Th1-effector cytokines such as IFN- $\gamma$ and/or TNF- $\alpha$ [28] and increased anti-tumor responses in patients with metastatic breast cancer treated with paclitaxel in combination with IMP321 [29]. Our data also showed that IMP321 supported the long-term expansion of tumor antigen-specific CD8 $\mathrm{T}$ cells with effector 


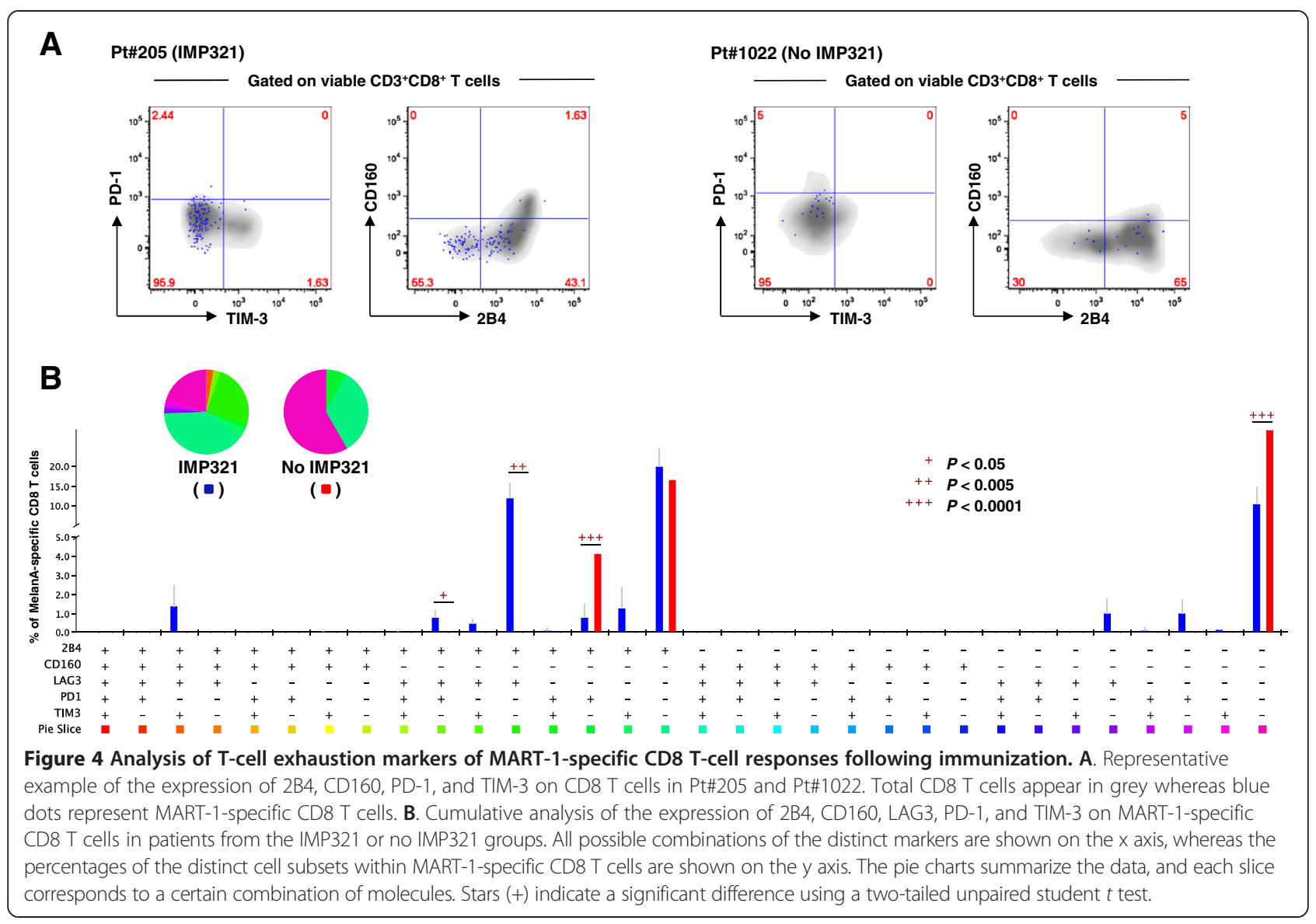

phenotypes including $\mathrm{CD}_{4} 5 \mathrm{RA}^{-} \mathrm{CCR}^{-}$and of CD45RA ${ }^{+} \mathrm{CCR}^{-}$cells. Antigen-experienced T cells comprise both effector memory $\left(\mathrm{T}_{\mathrm{EM}}\right)$ and central memory $\left(\mathrm{T}_{\mathrm{CM}}\right)$, which home respectively to inflamed tissues and lymphoid organs [30]. $\mathrm{T}_{\mathrm{EM}}$ cells are associated with development of a more robust, short-lived anti-tumor immunity [31].

Over the past decade, an overwhelming number of studies highlighted the association between the expression, and in particular the co-expression, of co-inhibitory receptors and a state of dysfunction or anergy also called exhaustion, as found in infectious diseases [26,32], and in cancer [33]. These pathways are also exploited by tumors to induce immune tolerance. In our study, we monitored the expression of a large panel of inhibitory receptors and, despite minor differences between groups, found no evidence of co-expression of those receptors on circulating T cells, thus indicating the lack of exhaustion of MART-1specific CD8 T-cell responses following immunization, both in the IMP321 and the control arm.

Of note, functional avidity is also a relevant component of CD8 T cells, as it reflects their sensitivity to cognate antigens, i.e. how prone $\mathrm{T}$ cells are to respond when they encounter low doses of antigen. It is well established that high-avidity CD8 T-cell responses are of higher efficacy against cancers [34]. Several studies aimed at increasing the avidity of anti-tumoral $\mathrm{T}$ cells [35,36]. Of interest, in the present study, we observed an increase in the functional avidity of MART-1-specific CD8 $\mathrm{T}$ cells after ACT of autologous cells and immunization. Unfortunately, our data do not allow us to establish the influence of the multiple immunizations (as compared to single immunization, for instance) nor the potential contribution of IMP321. The aforementioned increase in CD8 T-cell avidity upon immunization, however, is consistent with a recent study showing increase in T-cell avidity in HIV infection following antigen re-exposure (virus rebound) [23].

Similar to our experience with the MART-1 vaccine, many other cancer vaccines have also failed to induce measurable clinical benefit, often despite the induction of seemingly potent tumor antigen-specific Teff responses $[37,38]$. There are many potential explanations for this, but one that has received particular attention in recent years emphasizes the role of $\mathrm{CD} 4^{+} \mathrm{CD} 25^{+} \mathrm{FoxP}^{+}$ Tregs. Tregs play a central role in tempering immunity and in maintaining immune homeostasis. However, a growing body of evidence supports the concept that Tregs can also block the generation of effective anti- 


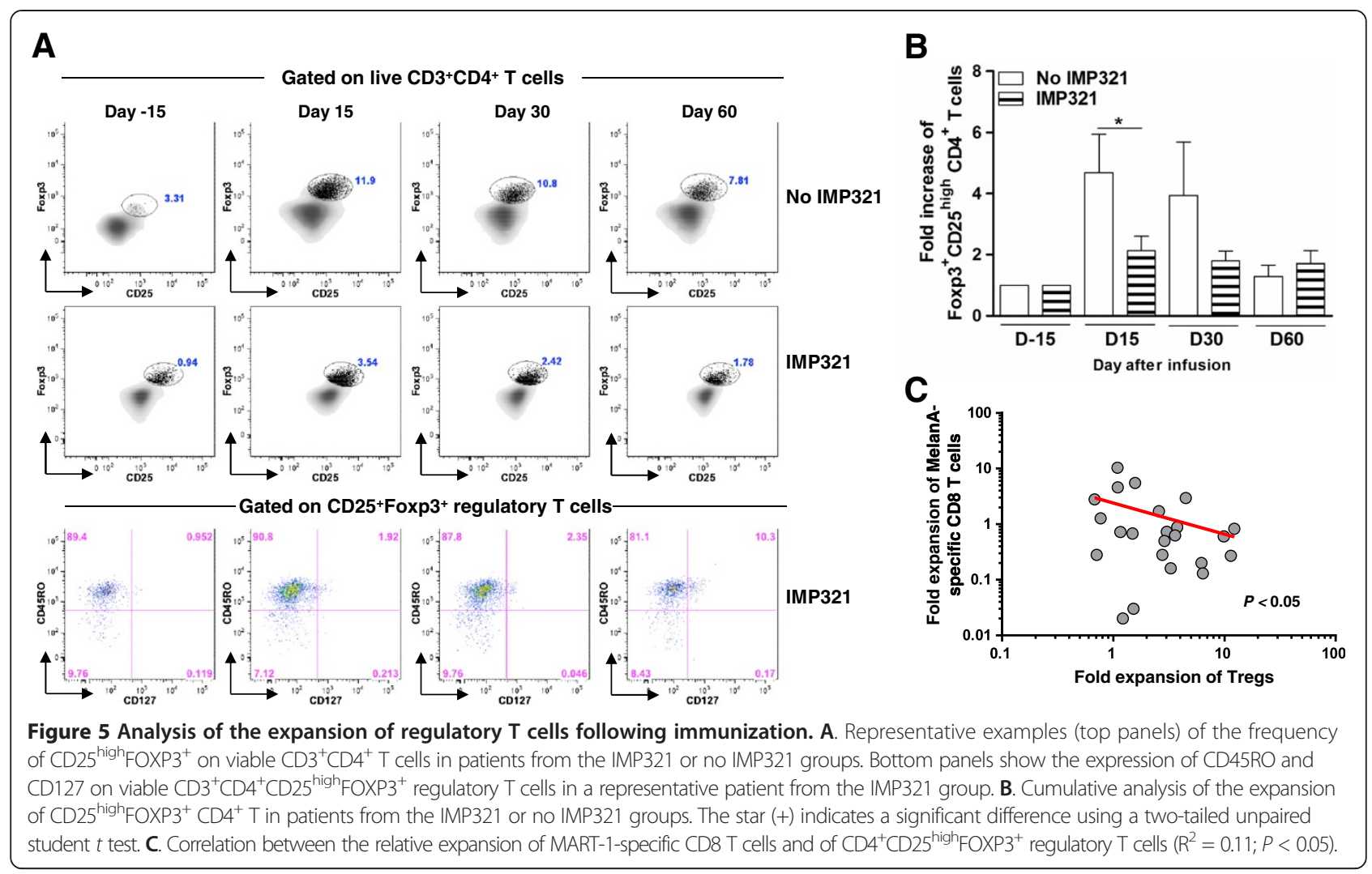

tumor immunity [39]. It is now well established that $\mathrm{CD}^{+}{ }^{+} \mathrm{CD} 25^{+}$Foxp $^{+}$Tregs encompass two categories of lymphocytes, natural and adaptive (or induced) Tregs. Until recently, evidence for the recognition of tumor antigens by Treg had been scarce, and it was unclear whether or not Tregs would be activated and expand in response to vaccination against tumor antigens. In recent years, however, a number of reports have identified Tregs specific for a range of tumor antigens in human cancer, including NY-ESO-1, survivin, TRP-1, gp100, MAGE-A3, and MART-1 [40]. Adaptive Tregs have been shown to develop in vivo following suboptimal antigen stimulation, in situations characterized by chronic inflammation, in the context of autoimmunity, allergy, and immune responses to tumors. In our study, we observed that the frequency of adaptive Tregs was significantly higher in the control group, compared with the group vaccinated with the same immunogen plus the adjuvant IMP321 and that their frequency inversely correlated with the expansion of MART-1-specific CD8 T cells. We speculate that such an increased Treg frequency in the control group may be due to the suboptimal antigenic stimulation provided in the MART-1 plus IFA51 vaccination in immune compromised hosts, which likely lead to a tolerogenic rather than tumor-specific response against MART-1. On the contrary, provision of the IMP321 to the vaccine was more immunogenic and resulted in significant increase of tetramer reactive MART-1 CD8 T cells with an effector phenotype and a decreased frequency of adaptive Tregs. This observation is in line with recent findings in a melanoma mouse model of peptide vaccination, which found that antigenspecific Tregs were induced following subcutaneous vaccination with either OVA or melanoma-derived peptides, with a restricted expansion of effector $\mathrm{T}$ cells. Whereas, the addition of the more potent adjuvants CpG-ODN or Poly (I: C) preferentially amplified effector $\mathrm{T}$ cells over Tregs [41].

Although the provision of IMP321 contributed to a significant increase of tetramer reactive MART-1 CD8 T cells with effector properties and a decreased frequency of adaptive Tregs, only one out of 6 patients in the IMP321 cohort achieved a short-lived PR (Additional file 4: Figure S3) that could not be confirmed at 24-weeks post treatment (as per RECIST criteria v1.1). One likely explanation for the low clinical activity observed in this study might rely on the use of non-tumor specific PBMCs instead of TILs, as effector cells in lymphodepleted hosts. Several studies have demonstrated superior anti-tumor reactivity in vitro and in vivo of TILs as compared with MART-1-specific CTL lines expanded from PBMCs $[1,42,43]$. In addition, lymphodepleting chemotherapy could have ablated antigen presenting cells, including skin dendritic cells, countering the potential 
effect of low-dose IMP321 on efficient antigenpresentation and T-cell priming at the vaccine site, thus hindering the clinical efficacy of our vaccination strategy. The use of vaccines based on tumor-loaded DCs [44] or short- plus long-peptide mix to favor helper $\mathrm{CD} 4^{+} \mathrm{T}$-cell responses could further improve immunogenicity and clinical efficacy. Among the outstanding challenges, foremost is the need to develop ACT strategies that are readily applicable and less labor-intensive. The recent development of faster and optimized protocols for TILs isolation and expansion should allow broader application of TILs-based approaches. Emerging techniques to engineer T-cell receptors (TCRs) or chimeric antigen receptors (CARs) using lymphocytes from peripheral blood may also offer new avenues in ACT and should result in increased clinical benefit.

\section{Conclusions}

The present regimen comprising multiple MART-1 vaccinations with or without IMP321 as an adjuvant in combination with lymphodepleting chemotherapy and adoptive transfer of autologous PBMCs was safe and immunogenic. In the arm receiving IMP321 we observed more robust and durable cellular antitumor immune responses, therefore we encourage further development of IMP321 for future immunotherapeutic strategies.

\section{Additional files}

Additional file 1: Table S1. Absolute numbers of PBMCs collected and infused for each patient.

Additional file 2: Figure S1. MART-1-specific CD8 T cells and T-cell counts at baseline and post-treatment. Frequencies of MART-1-specific CD8 T cells (A), total leukocyte counts (B), percentages of CD4 (C) and CD8 (D) T cells are shown prior to treatment (i.e. Bsl: baseline) and/or at day (D) 0, 15, 30, and 60 after PBMC infusion. Shown are median + interquartile ranges in panel $A$ and the mean \pm SD in panels $\mathbf{B}-\mathbf{D}$. Patients from the IMP321 and no IMP321 groups are shown in blue circles and red squares, respectively.

Additional file 3: Figure S2. Analysis of the functional avidity of MART-1specific CD8 T cells following immunization plus IMP321. A. Representative example of the functional avidity of MART-1-specific CD8 T cells prior to (blue circles) and then 60 days after (red triangles) ACT and immunization. PBMC were stimulated with decreasing concentration of MART-1 peptide and the frequency of IFN- $\gamma$-producing CD8 T cells was determined by ICS. The dashed line corresponds to half of the maximal response allowing the extrapolation of the $50 \%$ effect concentration $\left(E_{50}\right)$. B. Cumulative analysis showing the significant increase in the functional avidity of MART-1-specific CD8 T cells following immunization $(n=3)$.

Additional file 4: Figure S3. Short-lived partial response in a patient from the IMP321 group. Panel $\mathbf{A}$, baseline thorax-abdomen CT scan. Panel B, thorax-abdomen CT scan 30 days after completion of study treatment.

\section{Abbreviations}

IMP321: LAG-3lg fusion protein; TILs: Tumor-infiltrating lymphocytes; PBMCs: Peripheral blood mononuclear cells; Tregs: Regulatory T Iymphocytes; CTX: Cyclophosphamide; TLR: Toll-like receptor; DC: Dendritic cells; APC: Antigen-presenting cells; $E_{50}$ : Effect concentration 50\%; ACT: Adoptive cell therapy; MART-1: MelanA/MART-1.

\section{Competing interests}

$\mathrm{FT}$ is an employee and stock holder of Immutep S.A. $\mathrm{ER}, \mathrm{OM}, \mathrm{BH}, \mathrm{AS}, \mathrm{DES}, \mathrm{W}, J \mathrm{~L}, \mathrm{PR}, \mathrm{SL}$, and $\mathrm{AH}$ have no financial competing interests to disclose.

\section{Authors' contributions}

Conception and design: SL, W, JL, DES, and PR. Writing of the manuscript: $E R, S L$, and $A H$. Data analysis: ER, HB, AS, SL, and AH. Patients' recruitment: W, OM, ER, and SL. All authors have read and approved the manuscript.

\section{Acknowledgments}

This clinical trial was supported by a grant from Fond'Action Contre le Cancer to ER and SL. We appreciate the support and assistance of the CHUV physicians, nurses, and staff of the Medical Oncology Service, the Clinical Investigation Unit, and the Blood Bank Donor Room in obtaining patient samples. We also thank the clinical trial participants and healthy volunteers, who provided samples for research.

\section{Author details}

'Department of Oncology, Service of Medical Oncology, CHUV BH-06 1011 Lausanne, Switzerland. ${ }^{2}$ Laboratory of tumor immunobiology, Department of Oncology, University Hospital of Lausanne, Lausanne, Switzerland. ${ }^{3}$ Ludwig Center for Cancer Research at the University of Lausanne, Lausanne, Switzerland. ${ }^{4}$ Center of Experimental Therapeutics, Department of Oncology, University Hospital of Lausanne, Lausanne, Switzerland. ${ }^{5}$ Immutep, SA, Orsay, France. ${ }^{6}$ Current address: Merck-Serono, Darmstadt, Germany.

Received: 17 December 2013 Accepted: 31 March 2014 Published: 12 April 2014

\section{References}

1. Rosenberg SA, Yang JC, Sherry RM, Kammula US, Hughes MS, Phan GQ, Citrin DE, Restifo NP, Robbins PF, Wunderlich JR, Morton KE, Laurencot CM, Steinberg SM, White DE, Dudley ME: Durable complete responses in heavily pretreated patients with metastatic melanoma using T-cell transfer immunotherapy. Clin Cancer Res 2011, 17:4550-4557.

2. Hodi FS, O'Day SJ, McDermott DF, Weber RW, Sosman JA, Haanen JB, Gonzalez R, Robert C, Schadendorf D, Hassel JC, Akerley W, van den Eertwegh AJ, Lutzky J, Lorigan P, Vaubel JM, Linette GP, Hogg D, Ottensmeier CH, Lebbé C, Peschel C, Quirt I, Clark JI, Wolchok JD, Weber JS, Tian J, Yellin MJ, Nichol GM, Hoos A, Urba WJ: Improved survival with ipilimumab in patients with metastatic melanoma. N Engl J Med 2010, 363:711-723.

3. Topalian SL, Hodi FS, Brahmer JR, Gettinger SN, Smith DC, McDermott DF, Powderly JD, Carvajal RD, Sosman JA, Atkins MB, Leming PD, Spigel DR, Antonia SJ, Horn L, Drake CG, Pardoll DM, Chen L, Sharfman WH, Anders RA, Taube JM, McMiller TL, Xu H, Korman AJ, Jure-Kunkel M, Agrawal S, McDonald D, Kollia GD, Gupta A, Wigginton JM, Sznol M: Safety, activity, and immune correlates of anti-PD-1 antibody in cancer. N Engl J Med 2012, 366:2443-2454.

4. Hamid O, Robert C, Daud A, Hodi FS, Hwu WJ, Kefford R, Wolchok JD, Hersey P, Joseph RW, Weber JS, Dronca R, Gangadhar TC, Patnaik A, Zarour H, Joshua AM, Gergich K, Elassaiss-Schaap J, Algazi A, Mateus C, Boasberg P, Tumeh PC, Chmielowski B, Ebbinghaus SW, Li XN, Kang SP, Ribas A: Safety and tumor responses with lambrolizumab (anti-PD-1) in melanoma. $N$ Engl J Med 2013, 369:134-144.

5. Antony PA, Piccirillo CA, Akpinarli A, Finkelstein SE, Speiss PJ, Surman DR, Palmer DC, Chan CC, Klebanoff CA, Overwijk WW, Rosenberg SA, Restifo NP: CD8+ T cell immunity against a tumor/self-antigen is augmented by CD4+ T helper cells and hindered by naturally occurring $T$ regulatory cells. J Immunol 2005, 174:2591-2601.

6. Gattinoni L, Finkelstein SE, Klebanoff CA, Antony PA, Palmer DC, Spiess PJ, Hwang LN, Yu Z, Wrzesinski C, Heimann DM, Surh CD, Rosenberg SA, Restifo NP: Removal of homeostatic cytokine sinks by lymphodepletion enhances the efficacy of adoptively transferred tumor-specific CD8+ T cells. J Exp Med 2005, 202:907-912.

7. Paulos CM, Wrzesinski C, Kaiser A, Hinrichs CS, Chieppa M, Cassard L, Palmer DC, Boni A, Muranski P, Yu Z, Gattinoni L, Antony PA, Rosenberg SA, Restifo NP: Microbial translocation augments the function of adoptively transferred self/tumor-specific CD8+ T cells via TLR4 signaling. J Clin Invest 2007, 117:2197-2204 
8. Viaud S, Saccheri F, Mignot G, Yamazaki T, Daillere R, Hannani D, Enot DP, Pfirschke C, Engblom C, Pittet MJ, Schlitzer A, Ginhoux F, Apetoh L, Chachaty E, Woerther PL, Eberl G, Bérard M, Ecobichon C, Clermont D, Bizet C, Gaboriau-Routhiau V, Cerf-Bensussan N, Opolon P, Yessaad N, Vivier E, Ryffel B, Elson CO, Doré J, Kroemer G, Lepage P, et al: The intestinal microbiota modulates the anticancer immune effects of cyclophosphamide. Science 2013, 342:971-976.

9. Appay V, Voelter V, Rufer N, Reynard S, Jandus C, Gasparini D, Lienard D, Speiser DE, Schneider P, Cerottini JC, Romero P, Leyvraz S: Combination of transient lymphodepletion with busulfan and fludarabine and peptide vaccination in a phase I clinical trial for patients with advanced melanoma. J Immunother 2007, 30:240-250.

10. Laurent J, Speiser DE, Appay V, Touvrey C, Vicari M, Papaioannou A, Canellini G, Rimoldi D, Rufer N, Romero P, Leyvraz S, Voelter V: Impact of 3 different short-term chemotherapy regimens on lymphocyte-depletion and reconstitution in melanoma patients. J Immunother 2010, 33:723-734.

11. Speiser DE, Lienard D, Rufer N, Rubio-Godoy V, Rimoldi D, Lejeune F, Krieg AM, Cerottini JC, Romero P: Rapid and strong human CD8+ T cell responses to vaccination with peptide, IFA, and CpG oligodeoxynucleotide 7909 J Clin Invest 2005, 115:739-746.

12. Triebel F: LAG-3: a regulator of T-cell and DC responses and its use in therapeutic vaccination. Trends Immunol 2003, 24:619-622.

13. Triebel F, Hacene K, Pichon MF: A soluble lymphocyte activation gene-3 (sLAG-3) protein as a prognostic factor in human breast cancer expressing estrogen or progesterone receptors. Cancer Lett 2006, 235:147-153.

14. Andreae S, Piras F, Burdin N, Triebel F: Maturation and activation of dendritic cells induced by lymphocyte activation gene-3 (CD223) $\mathrm{J}$ Immunol 2002, 168:3874-3880.

15. El Mir S, Triebel F: A soluble lymphocyte activation gene-3 molecule used as a vaccine adjuvant elicits greater humoral and cellular immune responses to both particulate and soluble antigens. J Immunol 2000, 164:5583-5589.

16. Prigent $P$, El Mir S, Dreano M, Triebel F: Lymphocyte activation gene-3 induces tumor regression and antitumor immune responses. Eur J Immunol 1999, 29:3867-3876.

17. Buisson S, Triebel F: MHC class II engagement by its ligand LAG-3 (CD223) leads to a distinct pattern of chemokine and chemokine receptor expression by human dendritic cells. Vaccine 2003, 21:862-868.

18. Casati C, Camisaschi C, Rini F, Arienti F, Rivoltini L, Triebel F, Parmiani G, Castelli C: Soluble human LAG-3 molecule amplifies the in vitro generation of type 1 tumor-specific immunity. Cancer Res 2006, 66:4450-4460.

19. Speiser DE, Schwarz K, Baumgaertner P, Manolova V, Devevre E, Sterry W, Walden P, Zippelius A, Conzett KB, Senti G, Voelter V, Cerottini JP, Guggisberg D, Willers J, Geldhof C, Romero P, Kündig T, Knuth A, Dummer R, Trefzer U, Bachmann MF: Memory and effector CD8 T-cell responses after nanoparticle vaccination of melanoma patients. J Immunother 2010, 33:848-858.

20. Harari A, Enders FB, Cellerai C, Bart PA, Pantaleo G: Distinct profiles of cytotoxic granules in memory CD8 T cells correlate with function, differentiation stage, and antigen exposure. J Virol 2009, 83:2862-2871.

21. Roederer M, Nozzi JL, Nason MC: SPICE: Exploration and analysis of postcytometric complex multivariate datasets. Cytometry A 2011, 79A:167-174.

22. Harari A, Rozot V, Enders FB, Perreau M, Stalder JM, Nicod LP, Cavassini M, Calandra T, Blanchet CL, Jaton K, Faouzi M, Day CL, Hanekom WA, Bart PA, Pantaleo G: Dominant TNF-alpha+Mycobacterium tuberculosis-specific CD4+ $T$ cell responses discriminate between latent infection and active disease. Nat Med 2011, 17:372-376

23. Viganò S, Enders FB, Miconnet I, Cellerai C, Savoye AL, Rozot V, Perreau M, Faouzi M, Ohmiti K, Cavassini M, Bart PA, Pantaleo G, Harari A: Rapid perturbation in viremia levels drives increases in functional avidity of HIV-specific CD8 T cells. PLoS Pathog 2013, 9:e1003423.

24. Harari A, Dutoit V, Cellerai C, Bart PA, Du Pasquier RA, Pantaleo G: Functional signatures of protective antiviral T-cell immunity in human virus infections. Immunol Rev 2006, 211:236-254.

25. Cellerai C, Perreau M, Rozot V, Enders FB, Pantaleo G, Harari A: Proliferation capacity and cytotoxic activity are mediated by functionally and phenotypically distinct virus-specific CD8 T cells defined by interleukin7R \{alpha\} (CD127) and perforin expression. J Virol 2010, 84:3868-3878.

26. Vigano S, Perreau M, Pantaleo G, Harari A: Positive and negative regulation of cellular immune responses in physiologic conditions and diseases. Clin Dev Immunol 2012, 2012:485781.
27. Brignone C, Escudier B, Grygar C, Marcu M, Triebel F: A phase I pharmacokinetic and biological correlative study of IMP321, a novel MHC class II agonist, in patients with advanced renal cell carcinoma. Clin Cancer Res 2009, 15:6225-6231.

28. Brignone C, Grygar C, Marcu M, Schakel K, Triebel F: A soluble form of lymphocyte activation gene-3 (IMP321) induces activation of a large range of human effector cytotoxic cells. J Immunol 2007, 179:4202-4211.

29. Brignone C, Gutierrez M, Mefti F, Brain E, Jarcau R, Cvitkovic F, Bousetta N, Medioni J, Gligorov J, Grygar C, Marcu M, Triebel F: First-line chemoimmunotherapy in metastatic breast carcinoma: combination of paclitaxel and IMP321 (LAG-3/g) enhances immune responses and antitumor activity. J Transl Med 2010, 8:71.

30. Sallusto F, Lenig D, Forster R, Lipp M, Lanzavecchia A: Two subsets of memory $T$ lymphocytes with distinct homing potentials and effector functions. Nature 1999, 401:708-712.

31. Kilinc MO, Gu T, Harden JL, Virtuoso LP, Egilmez NK: Central role of tumorassociated CD8+ T effector/memory cells in restoring systemic antitumor immunity. J Immunol 2009, 182:4217-4225.

32. Wherry EJ: T cell exhaustion. Nat Immunol 2011, 12:492-499.

33. Baitsch L, Baumgaertner P, Devevre E, Raghav SK, Legat A, Barba L, Wieckowski S, Bouzourene H, Deplancke B, Romero P, Rufer N, Speiser DE: Exhaustion of tumor-specific CD8(+) T cells in metastases from melanoma patients. J Clin Invest 2011, 121:2350-2360

34. Zeh HJ 3rd, Perry-Lalley D, Dudley ME, Rosenberg SA, Yang JC: High avidity CTLs for two self-antigens demonstrate superior in vitro and in vivo antitumor efficacy. J Immunol 1999, 162:989-994.

35. Kuball J, Hauptrock B, Malina V, Antunes E, Voss RH, Wolfl M, Strong R, Theobald M, Greenberg PD: Increasing functional avidity of TCRredirected T cells by removing defined $\mathrm{N}$-glycosylation sites in the TCR constant domain. J Exp Med 2009, 206:463-475.

36. Lovgren T, Baumgaertner P, Wieckowski S, Devevre E, Guillaume P, Luescher I, Rufer N, Speiser DE: Enhanced cytotoxicity and decreased CD8 dependence of human cancer-specific cytotoxic T lymphocytes after vaccination with low peptide dose. Cancer Immunol Immunother 2012, 61:817-826.

37. Eggermont AM: Immunotherapy: Vaccine trials in melanoma - time for reflection. Nat Rev Clin Oncol 2009, 6:256-258.

38. Rosenberg SA, Yang JC, Restifo NP: Cancer immunotherapy: moving beyond current vaccines. Nat Med 2004, 10:909-915.

39. Nishikawa $H$, Sakaguchi S: Regulatory $T$ cells in tumor immunity. Int $J$ Cancer 2010, 127:759-767.

40. Francois V, Ottaviani S, Renkvist N, Stockis J, Schuler G, Thielemans K, Colau D, Marchand M, Boon T, Lucas S, van der Bruggen P: The CD4 (+) T-cell response of melanoma patients to a MAGE-A3 peptide vaccine involves potential regulatory T cells. Cancer Res 2009, 69:4335-4345.

41. Perret R, Sierro SR, Botelho NK, Corgnac S, Donda A, Romero P: Adjuvants that improve the ratio of antigen-specific effector to regulatory $T$ cells enhance tumor immunity. Cancer Res 2013, 73:6597-6608.

42. Mackensen A, Meidenbauer N, Vogl S, Laumer M, Berger J, Andreesen R: Phase I study of adoptive T-cell therapy using antigen-specific CD8+ T cells for the treatment of patients with metastatic melanoma. J Clin Oncol 2006, 24:5060-5069.

43. Yee C, Thompson JA, Byrd D, Riddell SR, Roche P, Celis E, Greenberg PD: Adoptive T cell therapy using antigen-specific CD8+ T cell clones for the treatment of patients with metastatic melanoma: in vivo persistence, migration, and antitumor effect of transferred T cells. Proc Nat'l Acad Sci U S A 2002, 99:16168-16173.

44. Kandalaft LE, Chiang CL, Tanyi J, Motz G, Balint K, Mick R, Coukos G: A Phase I vaccine trial using dendritic cells pulsed with autologous oxidized lysate for recurrent ovarian cancer. J Trans/ Med 2013, 11:149.

doi:10.1186/1479-5876-12-97

Cite this article as: Romano et al:: MART-1 peptide vaccination plus IMP321 (LAG-3lg fusion protein) in patients receiving autologous PBMCs after lymphodepletion: results of a Phase I trial. Journal of Translational Medicine 2014 12:97. 